\title{
The therapeutic agents that target ATP-sensitive potassium channels
}

\author{
HUSSEIN N. RUBAIY \\ School of Medicine \\ The Leeds Institute of Cardiovascular \\ and Metabolic Medicine \\ LIGHT Building 7.27 \\ University of Leeds, U.K.
}

Accepted September 15, 2015

Online published December 2, 2015

\begin{abstract}
ATP-sensitive potassium $\left(\mathrm{K}_{\mathrm{ATP}}\right)$ channels are a major drug target for the treatment of type- 2 diabetes. $\mathrm{K}_{\mathrm{ATP}}$ channels are ubiquitously expressed and link the metabolic state to electrical excitability. In pancreatic $\beta$-cells, $\mathrm{K}_{\mathrm{ATP}}$ channels are crucial in the regulation of glucose-induced insulin secretion. Also, $\mathrm{K}_{\text {ATP }}$ channels are involved in the protection against neuronal seizures and ischaemic stress in the heart, brain and in the regulation of vascular smooth muscle tone. Functional $\mathrm{K}_{\text {ATP }}$ channels are hetero-octamers composed of two subunits, a pore forming Kir6, which is a member of the inwardly rectifying potassium channels family, and a regulatory sulphonylurea receptor (SUR). In response to nucleotides and pharmaceutical agonists and antagonists, SUR allosterically regulates channel gating. The allosteric communication pathways between these two heterologus proteins in $\mathrm{K}_{\text {ATP }}$ channels are still poorly understood. This review will highlight the therapeutic agents that target $\mathrm{K}_{\mathrm{ATP}}$ channels and are used to treat diabetes and cardiovascular diseases.

Keywords: ATP-sensitive potassium channels, therapeutic agents, diabetes, cardiovascular, inwardly rectifying potassium channels, sulphonylurea receptor
\end{abstract}

Potassium channels play a significant role in shaping the excitability and firing patterns of cells (1). Potassium channels are divided into four major classes based on their structure: two, four, six and seven transmembrane-domain channels (2). There is large diversity within potassium channels, including calcium activated, voltage-gated, twin pore domain, and inwardly rectifying channel subtypes. Despite this large diversity, the members of the channel family have similarities, such as all of them having pore-lining P-loops with a consensus amino acid sequence (3).

A biophysical property of inwardly rectifying potassium (Kir) channels is that they conduct inward current more readily than outward current $(4,5)$. Kir channels are crucial for stabilizing the resting membrane potential and regulating excitability in many tissues $(1,4)$. This group consists of seven sub-families: Kir1 to Kir7. All members of the Kir channel

\footnotetext{
*Correspondence; e-mail: h.rubaiy@leeds.ac.uk
} 
family have the same basic structure, which consists of intracellular amino $(\mathrm{N})$ and carboxyl (C) termini and two putative membrane spanning segments (M1 and M2) flanking a pore-forming P-loop and signature sequence (6-8).

\section{THE ATP-SENSITIVE POTASSIUM CHANNELS}

The Kir channel proteins that have been identified comprise between 360 to 500 amino acids in length. All Kir members are regulated by the membrane phospholipid, phosphatidylinositol 4,5-bisphosphate $\left(\mathrm{PIP}_{2}\right)$, and some are also modulated by other regulatory factors or ligands, such as ATP and G-proteins, bearing their common names, ATP-sensitive $\left(\mathrm{K}_{\mathrm{ATP}}\right)$ and the G-protein-gated potassium channel (GRK) (8).

ATP-sensitive potassium $\left(\mathrm{K}_{\mathrm{ATP}}\right)$ channels, which are unique among potassium channels, were first described by Akinori Noma in 1983 (9). $\mathrm{K}_{\text {ATP }}$ channels have been identified in other tissues, including pancreatic $\beta$-cells (10), skeletal muscle cells (11), neuronal cells (12) and smooth muscle cells (13).

The classification of $\mathrm{K}_{\mathrm{ATP}}$ channels is mainly based on pharmacological criteria using the potassium channel openers (KCOs, agonists) or sulphonylureas (antagonists). $\mathrm{K}_{\mathrm{ATP}}$ channels are identified by subunit combinations of sulphonylurea receptor (SUR), SUR1, SUR2A and SUR2B, and inward rectifier (Kir), Kir6.1, Kir6.2, in different tissue types (14, 15).

\section{THE PORE-FORMING INWARD RECTIFIER POTASSIUM CHANNEL ISOFORMS 6 (KIR 6)}

The Kir6 subfamily is a member of the Kir channel family (16) and comprises the pore forming component of the $\mathrm{K}_{\text {ATP }}$ channel (17). There are two Kir6 isoforms, Kir6.1 and Kir6.2 (18). Kir6.1 and Kir6.2 isoforms are highly homologous and share $71 \%$ amino acid identity with each other (19). These two isoforms form functional $\mathrm{K}_{\text {ATP }}$ channels with sulphonylurea receptors (19).

\section{SULPHONYLUREA RECEPTOR}

Sulphonylurea receptor (SUR) polypeptides are members of the ATP-binding cassette protein of the ABCC/MRP family. Human ABC protein genes are classified into seven subfamilies: ABCA to ABCG according to their gene structure, sequence homology and phylogenetic relations (20). There are two genes encoding three isoforms of SUR: SUR1, which is encoded by the ABCC 8 gene, and SUR2 encoded by the ABCC9 gene. The latter can be transcribed into two different isoforms, SUR2A and SUR2B (21). These two SUR2 variants differ solely in the carboxyl-terminal due to alternative $3^{\prime}$-exon usage (22). In general, all $\mathrm{ABC}$ proteins contain a minimum of four structural domains: two transmembrane domains (TMDs) containing 6 to 8 transmembrane helices each and two cytosolic nucleotide binding domains (NBDs), which are involved in nucleotide binding and hydrolysis (23). SUR subunits consist of 17 transmembrane polypeptide segments clustered into three transmembrane domains (TMD), named TMD0, TMD1 and TMD2. TMD0 consists of the first five transmembrane segments and TMD1 and TMD2 consist of six segments each. There are two cytoplasmic nucleotide binding domains in each subunit. The first nucleotide binding domain NBD1 is located between transmembrane segments 11 and 12 and the 


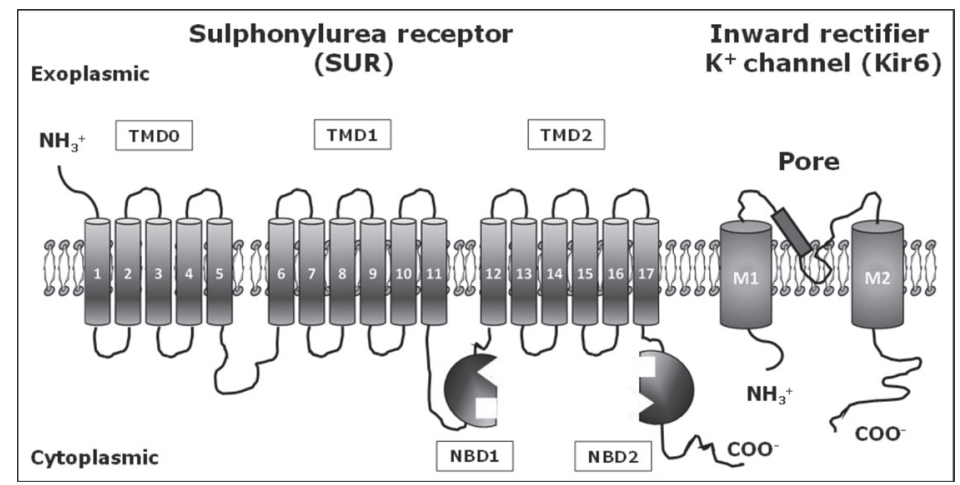

Fig. 1. Subunit structure of the ATP-sensitive potassium channel.

Schematic drawing showing the topology of the SUR and Kir6 subunits in $\mathrm{K}_{\text {ATP }}$ channels. The SUR subunit comprises the three transmembrane domains TMD0, TMD1 and TMD2, the two nucleotide binding domains NBD1 and NBD2, the extracellular N- and the intracellular C-termini and the poreforming Kir subunit. Each Kir subunit consists of two transmembrane helices M1 and M2 and a pore-forming region containing the pore-helix, and intracellular $\mathrm{N}$ - and C-termini.

second, NBD2, is located beyond the last transmembrane segment number 17 and forms part of the C-terminal domain $(21,24)$. Both the sequence and the structure of NBDs are highly conserved across all prokaryotic and eukaryotic $\mathrm{ABC}$ proteins. Each contains a conserved Walker A $\left(\mathrm{W}_{\mathrm{A}}\right)$ motif and a Walker $\mathrm{B}\left(\mathrm{W}_{\mathrm{B}}\right)$. These motifs catalyse ATP hydrolysis and are important for nucleotide regulation of the $\mathrm{ABC}$ proteins' functional activity (25).

As evidenced largely by Clement et al. (26), a functional $\mathrm{K}_{\text {ATP }}$ channel is an octameric complex composed of four SUR subunits and four Kir6 subunit, i.e., a 4:4 stoichiometry $\left(\mathrm{Kir6}_{4} / \mathrm{SUR}_{4}\right)$ (27). Binding of SUR to Kir subunits serves two purposes; first, to allow the translocation of the channel to the plasma membrane and, second, to contribute to the regulation of the channel by interaction between two subunits (28).

\section{THE ROLE OF ATP-SENSITIVE POTASSIUM CHANNELS IN DIFFERENT TISSUES AND CELL TYPES}

$\mathrm{K}_{\mathrm{ATP}}$ channels couple cell metabolism to electrical activity in nerve, muscle and endocrine cells and play an important role in various cellular functions as sensors of intracellular ATP and ADP coupled to electrical function (18). $\mathrm{K}_{\text {ATP }}$ channels have important roles in many tissues under both physiological and pathological conditions (29).

The $\mathrm{K}_{\text {ATP }}$ channel has a key role in the physiology of many cells and defects in the channel itself or in its regulation such as in hyper/hypo-glycemia, ischaemia, hormone secretion and excitability of muscles/neurons causes human diseases (30).

$\mathrm{K}_{\text {ATP }}$ channels are crucial in the regulation of glucose-induced insulin secretion (18). In pancreatic $\beta$-cells, an increase in ATP/ADP ratio, generated by glucose uptake and metabolism, closes the $\mathrm{K}_{\mathrm{ATP}}$ channels to elicit membrane depolarisation, calcium influx (opening of voltage-gated $\mathrm{Ca}^{2+}$ channels) and secretion of insulin, the primary hormone of glu- 
cose homeostasis. In hyperglycaemia, increased transport of glucose into the $\beta$-cells occurs resulting in an elevated intracellular ATP, promoting closure of the $\mathrm{K}_{\text {ATP }}$ channels and membrane depolarization (31). This $\mathrm{K}_{\mathrm{ATP}}$ channel mechanism can be mimicked by sulphonylurea drugs, for example, glibenclamide, which inhibits the $\mathrm{K}_{\mathrm{ATP}}$ channel directly in pancreatic $\beta$-cells (32).

Potassium channels are critical to cardiac excitability because they play fundamental roles in setting the resting membrane potential, RMP, and in repolarisation of the action potential (AP). Under normal conditions, the cardiac sarcolemmal $\mathrm{K}_{\mathrm{ATP}}$ channel is predominately closed (33). The channel activates during various forms of metabolic stress, including ischaemia, hypoxia, hyperglycemia, hypoglycaemia and inhibition of glycolysis and/or oxidative phosphorylation $(34,35)$.

In the vascular smooth muscle cells, $\mathrm{K}_{\mathrm{ATP}}$ channels are thought to play important roles such as mediating the response of the vascular smooth muscle to a variety of pharmacological and endogenous vasodilators and also to changes in metabolic activity that can directly influence blood flow in various tissues (36). Most of the $\mathrm{K}_{\text {АTP }}$ channels in vascular muscle cells are rather insensitive to ATP and they are activated by nucleoside diphosphates and inhibited by glibenclamide (37).

$\mathrm{K}_{\mathrm{ATP}}$ channels have been identified in various other tissues, including neurons, brain and skeletal muscle (30). $\mathrm{K}_{\text {ATP }}$ channels have been shown to be expressed in several regions of the brain, including the substantia nigra $(38,39)$ and in the hypothalamus $(40)$. Evidence has shown that the $\mathrm{K}_{\text {ATP }}$ channels are also expressed in the substantia nigra area of the brain (41). It has been proposed that $\mathrm{K}_{\mathrm{ATP}}$ channels play a role in the suppression of seizures in ATP-depleted conditions (42).

In the skeletal muscles, $\mathrm{K}_{\mathrm{ATP}}$ channels have been identified by electrophysiological methods (43). The channels are mainly located in the plasma membrane, appear in all fibre types and are active in the resting human muscle. $\mathrm{K}_{\text {ATP }}$ channels located in the sarcolemma contribute significantly to membrane permeability in the resting human muscle and are important for the interstitial $\mathrm{K}^{+}$balance (44).

\section{THE PHARMACOLOGY OF ATP-SENSITIVE POTASIUM CHANNELS}

$\mathrm{K}_{\mathrm{ATP}}$ channels are the major drug target and have the most therapeutic potential among potassium channels $(3,12,45)$. Pharmacological treatment of a number of clinical conditions, such as angina and Type 2 diabetes, are targeted on the $\mathrm{K}_{\text {ATP }}$ channel, though in different ways. To treat angina, agonists such as potassium channel openers (KCOs), e.g., nicorandil, are used to open the $\mathrm{K}_{\text {ATP }}$ channels in vascular smooth and cardiac muscles. In contrast to KCOs, antagonists such as sulphonylureas and related drugs are used to close $\mathrm{K}_{\mathrm{ATP}}$ channels in pancreatic $\beta$-cells with, for example, tolbutamide or glibenclamide. Both types, agonists and antagonists, target the various SUR subunits to either open or close the channels.

It has been shown that co-expression of Kir6.2/SUR2A, Kir6.2/SUR2B, and Kir6.1/ SUR2B reconstitutes the cardiac, smooth muscle and vascular smooth muscle $\mathrm{K}_{\text {ATP }}$ channels, respectively $(46,47)$. These channels have different sensitivities to ATP. They also show different responses to sulphonylurea drugs and potassium channel openers $(19,48$, 49) permitting tissue selectivity in $\mathrm{K}_{\mathrm{ATP}}$ channel directed therapies. 
Table I. Classification of sulphonylureas, the ATP-sensitive potassium channel antagonists

\begin{tabular}{|c|c|c|c|c|}
\hline \multicolumn{3}{|c|}{ Pharmacologic class } & Mechanism of action & Clinical use \\
\hline \multirow{3}{*}{ Sulphonylurea } & $\begin{array}{c}\text { First } \\
\text { generation }\end{array}$ & e.g., tolbutamide & \multirow{3}{*}{$\begin{array}{l}\text { blocking } \mathrm{K}_{\mathrm{ATP}} \text { channels in } \\
\text { pancreatic } \beta \text {-cells prevents } \mathrm{K}^{+} \\
\text {efflux and causes } \\
\text { depolarization of the plasma } \\
\text { membrane, then opens } \mathrm{Ca}^{2+} \\
\text { channels, causing influx of } \\
\mathrm{Ca}^{2+} \text { and insulin release }\end{array}$} & \multirow{3}{*}{$\begin{array}{l}\text { type } 2 \text { diabetes } \\
\text { mellitus }\end{array}$} \\
\hline & $\begin{array}{c}\text { Second } \\
\text { generation }\end{array}$ & e.g., glibenclamide & & \\
\hline & $\begin{array}{l}\text { Third } \\
\text { generation }\end{array}$ & e.g., glimepiride & & \\
\hline
\end{tabular}

\section{SULPHONYLUREAS}

Sulphonylurea compounds were originally intended to be antimicrobial agents during World War II. At that time, it was observed that a common side effect was hypoglycaemia, now known to be due to the inhibition of pancreatic $\beta$-cell $\mathrm{K}_{\text {ATP }}$ channels. Today, sulphonylureas are used to treat type 2 diabetes (Table I) (50-52).

The target of sulphonylurea is the plasma membrane expressed $\mathrm{K}_{\mathrm{ATP}}$ channel. At this site, sulphonylurea causes channel closure, which results in depolarization of the $\beta$-cell membrane and stimulation of insulin secretion (53). Kir6.2/SUR1 $\mathrm{K}_{\text {ATP }}$ channels are inhibited by glibenclamide (absolute inhibition constant $K_{\mathrm{i}} \sim 10 \mathrm{nmol} \mathrm{L}^{-1}$ ). Kir6.2/SUR2A, Kir6.2/ SUR2B and Kir6.1/SUR2B $K_{\text {ATP }}$ channels are inhibited with $\mathrm{K}_{\mathrm{i}}$ values in the low micromolar range $(16,19,48)$. The binding is isoform dependent; the $\beta$-cell isoform SUR1 binds only tolbutamide and gliclazide and SUR2A and SUR2B bind all other types of sulphonylureas $(51,54-57)$.

As mentioned earlier, $\mathrm{K}_{\mathrm{ATP}}$ channels are expressed ubiquitously however, sulphonylureas can cause undesired side effects since these drugs can cross-react with different $\mathrm{K}_{\text {ATP }}$ channel subtypes $(58,59)$. Chlorpropamide, acetohexamide, tolazamide and tolbutamide are the first-generation sulphonylureas and the action of these drugs is long lasting with considerable excretion in the urine (60). Hence, these drugs should be prescribed with cation for elderly patients with impaired kidney function (61).

Glyburide, glipizide and gliclazide are the second-generation sulphonylureas and they differ in pharmacokinetics and duration of action. It is worth mentioning that the second-generation sulfonylureas are more potent than the first-generation (60). A retrospective cohort study identified significant differences in ones risk of severe hypoglycaemia among users of individual sulphonylureas among older people (61). This study found relatively high incidence of hypoglycaemia in patients taking glyburide or chlorpropamide. Moreover, this study suggested a shorter-duration sulphonylureas such as glipizide elderly patients who cannot tolerate metformin as initial monotherapy (61).

Despite the differences in absorption and metabolism between the first- and secondgeneration sulphonylureas, they are equally effective in lowering blood glucose concentrations (62). Moreover, due to their structural characteristics, much lower doses of secondgeneration sulfonylureas are given than of the first generation (62). It has been reported 
that in patients with type 2 diabetes, glimepiride caused low incidence of severe hypoglycaemia compared to glibenclamide (63). Also, the duration of glimepiride action is up to 24 hours (64).

Hirst et al. (65) reported that sulphonylurea monotherapy reduced HbA1c by an average of $1.5 \%$ compared to that of placebo groups in a systematic review of double-blind randomized control trials. Sulphonylureas can lower the fasting blood glucose concentrations as extrapancreatic effects of these drugs. In other words, these drugs suppress the overnight hepatic glucose output $(61,66)$.

\section{POTASSIUM CHANNEL OPENERS}

Potassium channel openers are a chemically diverse group of agents, exemplified by pinacidil, levcromakalin, aprikalim, and nicorandil (Table II) $(3,12,14,25,51,67)$. These KCOs activate $\mathrm{K}_{\text {ATP }}$ channels (67-69). These agents possess high therapeutic potential in treating various clinical conditions such as hypertension, acute and chronic myocardial ischaemia, or congestive heart failure, and also in managing bronchial asthma, urinary incontinence and certain skeletal muscle myopathies $(3,45,69)$. The effect of opening the $\mathrm{K}_{\text {ATP }}$ channel with KCOs is causing a shift of the membrane potential towards the reversal potential for potassium and, thereby, reducing it to the cellular electrical excitability.

The $\mathrm{K}_{\mathrm{ATP}}$ channel subtype, which is stimulated by diazoxide, is Kir6.2/SUR1. However, these channels are not stimulated by pinacidil or cromakalim $(48,54)$. In contrast, Kir6.2/SUR2A $\mathrm{K}_{\text {ATP }}$ channels are not stimulated by diazoxide but are stimulated by pina-


both pinacidil and cromakalim $(16,70)$. Since nucleotide binding and/or hydrolysis at both NBDs of SUR subunits are taken to be crucial for the specific binding and action of these potassium channel openers $(19,54,70,71)$ and for slowing down the off-rate of pinacidil (72), it is believed that the differences in sulphonylurea sensitivity between these channel subtypes may be caused partially by differences in nucleotide sensitivity of the different SUR isoforms (19).

Table II. The potassium channel openers that target the ATP-sensitive potassium channels

\begin{tabular}{|c|c|c|c|c|}
\hline Agent & $\begin{array}{l}\text { Pharmacologic } \\
\text { class }\end{array}$ & Clinical use & As potential & Mechanism of action \\
\hline Diazoxide & \multirow{5}{*}{$\begin{array}{c}\text { potassium } \\
\text { channel opener, } \\
\text { vasodilator }\end{array}$} & hypertensive crises & & \multirow{5}{*}{$\begin{array}{l}\text { Opening of } \mathrm{K}_{\mathrm{ATP}} \\
\text { channels causing } \mathrm{K}^{+} \\
\text {efflux, hyperpolarization } \\
\text { of the cell membrane } \\
\text { and smooth muscle } \\
\text { relaxation leading to } \\
\text { vasodilation and drop in } \\
\text { blood pressure }\end{array}$} \\
\hline Minoxidil & & $\begin{array}{l}\text { hair growth stimulant, } \\
\text { severe hypertension }\end{array}$ & $\begin{array}{c}\text { antihypertensive } \\
\text { and }\end{array}$ & \\
\hline Nicorandil & & angina pectoris & $\begin{array}{l}\text { anti-asthmatic } \\
\text { agents }\end{array}$ & \\
\hline Pinacidil & & - & & \\
\hline Cromakalim & & - & & \\
\hline
\end{tabular}


The clinical use of potassium channel opening drugs has been limited due to the difficulties in developing tissue- and condition-selective $\mathrm{K}^{+}$channel-opening drugs (70). Different KCOs bind to different transmembrane polypeptide segments of the SUR. Within the 17 transmembrane polypeptide segments, the binding of pinacidil and cromakalim occurs at two domains within the helices numbered 16 and 17 (73), and in the cytoplasmic loop between segments 13 and $14(74,75)$. The binding site for diazoxide is not so well characterized. It is believed that diazoxide binding is nucleotide dependent (73). In SUR1, diazoxide binding has been mapped to bind between helices 8 to 11 and in the C-terminal region incorporating helix 17 and NBD2 (73).

One of KCOs functions is to activate sarcK $\mathrm{ATP}_{\mathrm{P}}$ on vascular smooth muscle cells and cardiac myocytes, which leads to potassium ion efflux and membrane hyperpolarization. This in turn will reduce calcium influx and reduce the duration of the action potential, resulting in a negative inotropic effect in cardiomyocytes and vasodilatation of blood vessels $(76,77)$. First-generation drugs, including cromakalim and pinacidil, were aimed at treating hypertension; however, such medications failed to achieve clear benefits over angiotensin-converting enzyme inhibitors or calcium antagonists (78).

Selective KCO bimakalin did not show any anti-ischemic benefits in patients suffering from coronary artery disease during exercise-induced angina pectoris. However, the drug did cause a dose dependent vasodilatory activity (79). Studies, including one by Ueda et al. (80), have shown that KCO nicorandil administered intravenously can reduce the occurrence of ventricular fibrillation and QT dispersion in patients with acute myocardial infarction (AMI) undergoing successful coronary angioplasty. According to the Ueda study, this would prevent the occurrence of cardiac events following successful percutaneous transluminal coronary angioplasty for AMI patients. The administration of nicorandil to patients with stable angina in an angina (IONA) study (81) effectively reduced the rates of the combined primary endpoint of coronary heart disease mortality, myocardial infarction, or admission for chest pain, and the secondary endpoint of coronary heart disease mortality, myocardial infarction, or unstable angina and the rates of cardiovascular events.

Another $\mathrm{K}_{\mathrm{ATP}}$ channel opener, levosimendan, which is a calcium sensitizer and inodilator, has been shown to significantly reduce pulmonary capillary wedge pressure in patients with severe low-output heart failure following cardiac surgery as well as in a case of peripartum cardiomyopathy (82). In controlled trials, levosimendan has been shown to decrease mortality rates in patients with severe low-output heart failure and in patients with left ventricular failure after $\operatorname{AMI}(83,84)$.

\section{CONCLUSIONS}

In response to nucleotides and pharmaceutical agonists and antagonists, SUR allosterically regulate the $\mathrm{K}_{\text {ATP }}$ channel gating in a functional $\mathrm{K}_{\text {ATP }}$ channel complex $\mathrm{Kir}_{4} /$ $\mathrm{SUR}_{4}$. However, the transduction pathways for allosteric communication, which make the functional link between the pore forming Kir6 and the regulatory SUR subunits of $\mathrm{K}_{\text {ATP }}$ channels remain poorly understood.

To design novel and more effective drugs for the treatment of diabetes, high blood pressure and/or use as a cardioprotective agent in heart attack or cardiac surgery (therapeutic importance), the three-dimensional crystal structure of the functional $\mathrm{K}_{\mathrm{ATP}}$ channel 
needs to be determined. The crystal structure will clarify the allosteric communications between $\mathrm{K}_{\text {АтP }}$ channel subunits that induce the conformational changes and channel gating.

\section{REFERENCES}

1. B. Hille, Ion Channels of Excitable Membranes, Sinauer Associates, Sunderland 2001, p. 814.

2. S. Choe, Potassium channel structures, Nat. Rev. Neurosci. 3 (2002) 115-121; DOI: 10.1038/nrn727.

3. C. C. Shieh, M. Coghlan, J. P. Sullivan and M. Gopalakrishnan, Potassium channels: molecular defects, diseases, and therapeutic opportunities, Pharmacol. Rev. 52 (2000) 557-594.

4. C. A. Doupnik, N. Davidson and H. A. Lester, The inward rectifier potassium channel family, Curr. Opin. Neurobiol. 5 (1995) 268-277; DOI: 10.1016/0959-4388(95)80038-7.

5. C. G. Nichols and A. N. Lopatin, Inward rectifier potassium channels, Annu. Rev. Physiol. 59 (1997) 171-191; DOI: 10.1146/annurev.physiol.59.1.171.

6. D. Bichet, F. A. Haass and L. Y. Jan, Merging functional studies with structures of inward-rectifier K(+) channels, Nat. Rev. Neurosci. 4 (2003) 957-967; DOI: 10.1038/nrn1244.

7. D. E. Logothetis, D. Lupyan and A. Rosenhouse-Dantsker, Diverse Kir modulators act in close proximity to residues implicated in phosphoinositide binding, J. Physiol. 582 (2007) 953-965; DOI: 10.1113/jphysiol.2007.133157.

8. L. H. Xie, S. A. John, B. Ribalet and J. N. Weiss, Activation of inwardly rectifying potassium (Kir) channels by phosphatidylinosital-4,5-bisphosphate (PIP2): interaction with other regulatory ligands, Prog. Biophys. Mol. Biol. 94 (2007) 320-335; DOI: 10.1016/j.pbiomolbio.2006.04.001.

9. A. Noma, ATP-regulated $\mathrm{K}^{+}$channels in cardiac muscle, Nature 305 (1983) 147-148; DOI: 10.1038/305147a0.

10. D. L. Cook and C. N. Hales, Intracellular ATP directly blocks $\mathrm{K}^{+}$channels in pancreatic B-cells, Nature 311 (1984) 271-273; DOI: 10.1038/311271a0.

11. A. E. Spruce, N. B. Standen and P. R. Stanfield, Voltage-dependent ATP-sensitive potassium channels of skeletal muscle membrane, Nature 316 (1985) 736-738; DOI: 10.1038/316736a0.

12. S. J. Ashcroft and F. M. Ashcroft, Properties and functions of ATP-sensitive K-channels, Cell. Signal. 2 (1990) 197-214; DOI 10.1016/0898-6568(90)90048-F.

13. N. B. Standen, J. M. Quayle, N. W. Davies, J. E. Brayden, Y. Huang and M. T. Nelson, Hyperpolarizing vasodilators activate ATP-sensitive $\mathrm{K}^{+}$channels in arterial smooth muscle, Science 245 (1989) 177-180; DOI: 10.1126/science.2501869.

14. L. Aguilar-Bryan and J. Bryan, Molecular biology of adenosine triphosphate-sensitive potassium channels, Endocr. Rev. 20 (1999) 101-135; DOI: 10.1210/edrv.20.2.0361.

15. G. E. Billman, The cardiac sarcolemmal ATP-sensitive potassium channel as a novel target for anti-arrhythmic therapy, Pharmacol. Ther. 120 (2008) 54-70; DOI: 10.1016/j.pharmthera.2008.07.004.

16. S. Isomoto and Y. Kurachi, [Molecular and biophysical aspects of potassium channels], Nihon Rinsho. (Jpn. J. Clin. Med.) 54 (1996) 660-666.

17. J. Bryan and L. Aguilar-Bryan, Sulfonylurea receptors: ABC transporters that regulate ATP-sensitive K(+) channels, Biochim. Biophys. Acta 1461 (1999) 285-303; DOI: 10.1016/S0005-2736(99)001649.

18. N. Inagaki and S. Seino, ATP-sensitive potassium channels: structures, functions, and pathophysiology, Jpn. J. Physiol. 48 (1998) 397-412; DOI: 10.2170/jjphysiol.48.397.

19. M. Matsuo, K. Tanabe, N. Kioka, T. Amachi and K. Ueda, Different binding properties and affinities for ATP and ADP among sulfonylurea receptor subtypes, SUR1, SUR2A, and SUR2B, J. Biol. Chem. 275 (2000) 28757-28763; DOI: 10.1074/jbc.M004818200. 
20. M. Dean, A. Rzhetsky and R. Allikmets, The human ATP-binding cassette (ABC) transporter superfamily, Genome Res. 11 (2001) 1156-1166; DOI: 10.1101/gr.184901.

21. L. Aguilar-Bryan, J. P. Clement IV, G. Gonzalez, K. Kunjilwar, A. Babenko and J. Bryan, Toward understanding the assembly and structure of KATP channels, Physiol. Rev. 78 (1998) 227-245.

22. B. G. Gabrielsson, A. C. Karlsson, M. Lonn, L. E. Olofsson, J. M. Johansson, J. S. Torgerson, L. Sjostrom, B. Carlsson, S. Eden and L. M. Carlsson, Molecular characterization of a local sulfonylurea system in human adipose tissue, Mol. Cell. Biochem. 258 (2004) 65-71; DOI: 10.1023/B:MCBI.0000012837.11847.c8.

23. C. F. Higgins, ABC transporters: physiology, structure and mechanism-an overview, Res. Microbiol. 152 (2001) 205-210.

24. J. E. Walker, M. Saraste, M. J. Runswick and N. J. Gay, Distantly related sequences in the alphaand beta-subunits of ATP synthase, myosin, kinases and other ATP-requiring enzymes and a common nucleotide binding fold, EMBO J. 1 (1982) 945-951.

25. R. Mannhold, KATP channel openers: structure-activity relationships and therapeutic potential, Med. Res. Rev. 24 (2004) 213-266; DOI: 10.1002/med.10060.

26. J. P. Clement IV, K. Kunjilwar, G. Gonzalez, M. Schwanstecher, U. Panten, L. Aguilar-Bryan and J. Bryan, Association and stoichiometry of K(ATP) channel subunits, Neuron 18 (1997) 827-838; DOI: 10.1016/S0896-6273(00)80321-9.

27. D. Enkvetchakul, G. Loussouarn, E. Makhina and C. G. Nichols, ATP interaction with the open state of the K(ATP) channel, Biophys. J. 80 (2001) 719-728; DOI: 10.1016/S0006-3495(01)76051-1.

28. M. A. Burke, R. K. Mutharasan and H. Ardehali, The sulfonylurea receptor, an atypical ATP-bin ding cassette protein, and its regulation of the KATP channel, Circ. Res. 102 (2008) 164-176; DOI: 10.1161/CIRCRESAHA.107.165324.

29. F. M. Ashcroft and F. M. Gribble, Correlating structure and function in ATP-sensitive $\mathrm{K}^{+}$channels, Trends Neurosci. 21 (1998) 288-294; DOI: 10.1016/S0166-2236(98)01225-9.

30. S. Seino, Physiology and pathophysiology of K(ATP) channels in the pancreas and cardiovascular system: a review, J. Diabetes Compl. 17 (2003) 2-5; DOI: 10.1016/S1056-8727(02)00274-X.

31. S. Sattiraju, S. Reyes, G. C. Kane and A. Terzic, K(ATP) channel pharmacogenomics: from bench to bedside, Clin. Pharmacol. Ther. 83 (2008) 354-357; DOI: 10.1038/sj.clpt.6100378.

32. K. Hussain and K. E. Cosgrove, From congenital hyperinsulinism to diabetes mellitus: the role of pancreatic beta-cell KATP channels, Pediatr. Diabetes 6 (2005) 103-113; DOI: 10.1111/j.1399-543X.2005.00109.x.

33. N. Deutsch, T. S. Klitzner, S. T. Lamp and J. N. Weiss, Activation of cardiac ATP-sensitive $\mathrm{K}^{+}$current during hypoxia: correlation with tissue ATP levels, Am. J. Physiol. 261 (1991) H671-6.

34. Y. G. Kwak, S. K. Park, U. H. Kim, M. K. Han, J. S. Eun, K. P. Cho and S. W. Chae, Intracellular ADP-ribose inhibits ATP-sensitive $\mathrm{K}^{+}$channels in rat ventricular myocytes, Am. J. Physiol. 271 (1996) C464-8.

35. H. Yokoshiki, M. Sunagawa, T. Seki and N. Sperelakis, ATP-sensitive $\mathrm{K}^{+}$channels in pancreatic, cardiac, and vascular smooth muscle cells, Am. J. Physiol. 274 (1998) C25-C37.

36. J. E. Brayden, Functional roles of KATP channels in vascular smooth muscle, Clin. Exp. Pharmacol. Physiol. 29 (2002) 312-316; DOI: 10.1046/j.1440-1681.2002.03650.x.

37. M. Yamada, S. Isomoto, S. Matsumoto, C. Kondo, T. Shindo, Y. Horio and Y. Kurachi, Sulphonylurea receptor 2B and Kir6.1 form a sulphonylurea-sensitive but ATP-insensitive $\mathrm{K}^{+}$channel, J. Physiol. 499 (1997) 715-20; DOI: 10.1113/jphysiol.1997.sp021963.

38. J. Roper and F. M. Ashcroft, Metabolic inhibition and low internal ATP activate K-ATP channels in rat dopaminergic substantia nigra neurones, Pflugers Arch. 430 (1995) 44-54; DOI: 10.1007/ BF00373838. 
39. I. M. Stanford and M. G. Lacey, Electrophysiological investigation of adenosine trisphosphatesensitive potassium channels in the rat substantia nigra pars reticulata, Neuroscience 74 (1996) 499-509; DOI: 10.1016/0306-4522(96)00151-0.

40. M. L. Ashford, P. R. Boden and J. M. Treherne, Tolbutamide excites rat glucoreceptive ventromedial hypothalamic neurones by indirect inhibition of ATP-K' $\mathrm{K}^{+}$hannels, Br. J. Pharmacol. 101 (1990) 531-540; DOI: 10.1111/j.1476-5381.1990.tb14116.x.

41. M. Chien, I. Morozova, S. Shi, H. Sheng, J. Chen, S. M. Gomez, G. Asamani, K. Hill, J. Nuara, M. Feder, J. Rineer, J. J. Greenberg, V. Steshenko, S. H. Park, B. Zhao, E. Teplitskaya, J. R. Edwards, S. Pampou, A. Georghiou, I. C. Chou, W. Iannuccilli, M. E. Ulz, D. H. Kim, A. Geringer-Sameth, C. Goldsberry, P. Morozov, S. G. Fischer, G. Segal, X. Qu, A. Rzhetsky, P. Zhang, E. Cayanis, P. J. De Jong, J. Ju, S. Kalachikov, H. A. Shuman and J. J. Russo, The genomic sequence of the accidental pathogen Legionella pneumophila, Science 305 (2004) 1966-1968; DOI: 10.1126/science.1099776.

42. K. Yamada and N. Inagaki, ATP-sensitive $\mathrm{K}(+)$ channels in the brain: sensors of hypoxic conditions, News Physiol. Sci. 17 (2002) 127-30.

43. N. W. Davies, Modulation of ATP-sensitive $\mathrm{K}^{+}$channels in skeletal muscle by intracellular protons, Nature 343 (1990) 375-377; DOI: 10.1038/343375a0.

44. J. J. Nielsen, M. Kristensen, Y. Hellsten, J. Bangsbo and C. Juel, Localization and function of ATPsensitive potassium channels in human skeletal muscle, Am. J. Physiol. Regul. Integr. Comp. Physiol. 284 (2003) R558-R63; DOI: 10.1152/ajpregu.00303.2002.

45. S. M. Gopalakrishnan, C. Chen and M. F. Lokhandwala, Identification of alpha 1-adrenoceptor subtypes in rat renal proximal tubules, Eur. J. Pharmacol. 250 (1993) 469-472; DOI: 10.1016/00142999(93)90036-H.

46. A. P. Babenko, L. Aguilar-Bryan and J. Bryan, A view of sur/KIR6.X, KATP channels, Annu. Rev. Physiol. 60 (1998) 667-687; DOI: 10.1146/annurev.physiol.60.1.667.

47. S. Seino, ATP-sensitive potassium channels: a model of heteromultimeric potassium channel/ receptor assemblies, Annu. Rev. Physiol. 61 (1999) 337-362; DOI: 10.1146/annurev.physiol.61.1.337.

48. N. Inagaki, T. Gonoi, J. P. Clement IV, N. Namba, J. Inazawa, G. Gonzalez, L. Aguilar-Bryan, S. Seino and J. Bryan, Reconstitution of $I_{\text {KATP: }}$ an inward rectifier subunit plus the sulfonylurea receptor, Science 270 (1995) 1166-1170; DOI: 10.1126/science.270.5239.1166.

49. S. Isomoto, C. Kondo, M. Yamada, S. Matsumoto, O. Higashiguchi, Y. Horio, Y. Matsuzawa and Y. Kurachi, A novel sulfonylurea receptor forms with BIR (Kir6.2) a smooth muscle type ATP-sensitive $\mathrm{K}^{+}$channel, J. Biol. Chem. 271 (1996) 24321-24324; DOI: 10.1074/jbc.271.40.24321.

50. P. Proks, F. Reimann, N. Green, F. Gribble and F. Ashcroft, Sulfonylurea stimulation of insulin secretion, Diabetes 51 (2002) S368-S376; DOI: 10.2337/diabetes.51.2007.S368.

51. F. M. Gribble and F. Reimann, Pharmacological modulation of K(ATP) channels, Biochem. Soc. Trans. 30 (2002) 333-339; DOI: 10.1042/ bst0300333.

52. T. Hamaguchi, T. Hirose, H. Asakawa, Y. Itoh, K. Kamado, K. Tokunaga, K. Tomita, H. Masuda, N. Watanabe and M. Namba, Efficacy of glimepiride in type 2 diabetic patients treated with glibenclamide, Diabetes Res. Clin. Pract. 66 (2004) S129-S132; DOI: 10.1016/j.diabres.2003.12.012.

53. N. C. Sturgess, M. L. Ashford, D. L. Cook and C. N. Hales, The sulphonylurea receptor may be an ATP-sensitive potassium channel, Lancet 326 (1985) 474-475; DOI: 10.1016/S0140-6736(85)90403-9.

54. F. M. Gribble, S. J. Tucker and F. M. Ashcroft, The interaction of nucleotides with the tolbutamide block of cloned ATP-sensitive $\mathrm{K}^{+}$channel currents expressed in Xenopus oocytes: a reinterpretation, J. Physiol. 504 (1997) 35-45; DOI: 10.1111/j.1469-7793.1997.00035.x.

55. F. M. Gribble and F. M. Ashcroft, Differential sensitivity of beta-cell and extrapancreatic K(ATP) channels to gliclazide, Diabetologia 42 (1999) 845-848; DOI: 10.1007/s001250051236.

56. F. Reimann, P. Proks and F. M. Ashcroft, Effects of mitiglinide (S 21403) on Kir6.2/SUR1, Kir6.2/ SUR2A and Kir6.2/SUR2B types of ATP-sensitive potassium channel, Br. J. Pharmacol. 132 (2001) 1542-1548; DOI: 10.1038/sj.bjp.0703962. 
57. Y. Sunaga, T. Gonoi, T. Shibasaki, K. Ichikawa, H. Kusama, H. Yano and S. Seino, The effects of mitiglinide (KAD-1229), a new anti-diabetic drug, on ATP-sensitive $\mathrm{K}^{+}$channels and insulin secretion: comparison with the sulfonylureas and nateglinide, Eur. J. Pharmacol. 431 (2001) 119-125; DOI: 10.1016/S0014-2999(01)01412-1.

58. F. M. Ashcroft and F. M. Gribble, Tissue-specific effects of sulfonylureas: lessons from studies of cloned K(ATP) channels, J. Diabetes Compl. 14 (2000) 192-196; DOI: 10.1016/S1056-8727(00)00081-7.

59. S. Hu, S. Wang and B. E. Dunning, Tissue selectivity of antidiabetic agent nateglinide: study on cardiovascular and beta-cell K(ATP) channels, J. Pharmacol. Exp. Ther. 291 (1999) 1372-1379.

60. A. Melander, Kinetics-effect relations of insulin-releasing drugs in patients with type 2 diabetes: brief overview, Diabetes 53 (2004) S151-S155; DOI: 10.2337/diabetes.53.suppl_3.S151.

61. R. I. Shorr, W. A. Ray, J. R. Daugherty and M. R. Griffin, Individual sulfonylureas and serious hypoglycemia in older people, J. Am. Geriatr. Soc. 44 (1996) 751-755; DOI: 10.1111/j.1532-5415.1996. tb03729.x.

62. A. Jonsson, T. Rydberg, G. Ekberg, B. Hallengren and A. Melander, Slow elimination of glyburide in NIDDM subjects, Diabetes Care 17 (1994) 142-145; DOI: 10.2337/diacare.17.2.142.

63. A. Holstein, A. Plaschke and E. H. Egberts, Lower incidence of severe hypoglycaemia in patients with type 2 diabetes treated with glimepiride versus glibenclamide, Diabetes Metab. Res. Rev. 17 (2001) 467-473; DOI: 10.1002/dmrr.235.

64. A. Basit, M. Riaz and A. Fawwad, Glimepiride: evidence-based facts, trends, and observations, Vasc. Health Risk Manag. 8 (2012) 463-472; DOI: 10.2147/HIV.S33194

65. J. A. Hirst, A. J. Farmer, A. Dyar, T. W. Lung and R. J. Stevens, Estimating the effect of sulfonylurea on HbA1c in diabetes: a systematic review and meta-analysis, Diabetologia 56 (2013) 973-984; DOI: 10.1007/s00125-013-2856-6.

66. K. Kaku, Y. Inoue and T. Kaneko, Extrapancreatic effects of sulfonylurea drugs, Diabetes Res. Clin. Pract. 28 (1995) S105-S108; DOI: 10.1016/0168-8227(95)01078-R.

67. A. Terzic, A. Jahangir and Y. Kurachi, Cardiac ATP-sensitive $\mathrm{K}^{+}$channels: regulation by intracellular nucleotides and $\mathrm{K}^{+}$channel-opening drugs, Am. J. Physiol. 269 (1995) C525-C545.

68. J. P. Arena and R. S. Kass, Activation of ATP-sensitive K channels in heart cells by pinacidil: dependence on ATP, Am. J. Physiol. 257 (1989) H2092-2096.

69. G. Edwards, T. Ibbotson and A. H. Weston, Levcromakalim may induce a voltage-independent K-current in rat portal veins by modifying the gating properties of the delayed rectifier, Br. J. Pharmacol. 110 (1993) 1037-1048; DOI: 10.1111/j.1476-5381.1993.tb13918.x.

70. M. Schwanstecher, C. Sieverding, H. Dorschner, I. Gross, L. Aguilar-Bryan, C. Schwanstecher and J. Bryan, Potassium channel openers require ATP to bind to and act through sulfonylurea receptors, EMBO J. 17 (1998) 5529-5535; DOI: 10.1093/emboj/17.19.5529.

71. S. Shyng, T. Ferrigni and C. G. Nichols, Regulation of KATP channel activity by diazoxide and MgADP. Distinct functions of the two nucleotide binding folds of the sulfonylurea receptor, $J$. Gen. Physiol. 110 (1997) 643-654; DOI: 10.1085/jgp.110.6.643.

72. F. M. Gribble, F. Reimann, R. Ashfield and F. M. Ashcroft, Nucleotide modulation of pinacidil stimulation of the cloned K(ATP) channel Kir6.2/SUR2A, Mol. Pharmacol. 57 (2000) 1256-1261.

73. C. Moreau, A. L. Prost, R. Derand and M. Vivaudou, SUR, ABC proteins targeted by KATP channel openers, J. Mol. Cell Cardiol. 38 (2005) 951-963; DOI: 10.1016/j.yjmcc.2004.11.030.

74. A. P. Babenko, G. Gonzalez and J. Bryan, Pharmaco-topology of sulfonylurea receptors. Separate domains of the regulatory subunits of $\mathrm{K}(\mathrm{ATP})$ channel isoforms are required for selective interaction with K(+) channel openers, J. Biol. Chem. 275 (2000) 717-720; DOI: 10.1074/jbc.275.2.717.

75. I. Uhde, A. Toman, I. Gross, C. Schwanstecher and M. Schwanstecher, Identification of the potassium channel opener site on sulfonylurea receptors, J. Biol. Chem. 274 (1999) 28079-28082; DOI: 10.1074/jbc.274.40.28079. 
76. G. Edwards and A. H. Weston, Potassium channel openers and vascular smooth muscle relaxation, Pharmacol. Ther. 48 (1990) 237-258; DOI: 10.1016/0163-7258(90)90082-D.

77. A. H. Weston, J. Longmore, D. T. Newgreen, G. Edwards, K. M. Bray and S. Duty, The potassium channel openers: a new class of vasorelaxants, Blood Vessels. 27 (1990) 306-313; DOI $10.1159 / 000158823$

78. J. C. Clapham, In Vivo Vascular Effects of Potassium Channel Activation in Isolated Blood Vessels, in Potassium Channels and Their Modulators (Ed. J. M. Evans), 1st ed., Taylor \& Francis, London 1996, pp. 448 .

79. M. Burian, M. Piske, D. Petkovic and V. Mitrovic, Lack of anti-ischemic efficacy of the potassium channel opener bimakalim in patients with stable angina pectoris, Cardiovasc. Drugs Ther. 18 (2004) 37-46; DOI: 10.1023/B:CARD.0000025754.08942.03.

80. H. Ueda, Y. Nakayama, K. Tsumura, K. Yoshimaru, T. Hayashi and J. Yoshikawa, Intravenous nicorandil can reduce the occurrence of ventricular fibrillation and QT dispersion in patients with successful coronary angioplasty in acute myocardial infarction, Can. J. Cardiol. 20 (2004) 625-629.

81. I. S. Group, Effect of nicorandil on coronary events in patients with stable angina: the impact of nicorandil in angina (IONA) randomised trial, Lancet 359 (2002) 1269-1275; DOI: 10.1016/S01406736(02)08265-X.

82. D. J. Milligan and A. M. Fields, Levosimendan: calcium sensitizer and inodilator, Anesthesiol. Clin. 28 (2010) 753-760; DOI: 10.1016/j.anclin.2010.08.003.

83. F. Follath, J. G. F. Cleland, H. Just, J. G. Y. Papp, H. Scholz, K. Peuhkurinen, V. P. Harjola, V. Mitrovic, M. Abdalla, E.-P. Sandell and L. Lehtonen, for the Steering Committee and Investigators of the Levosimendan Infusion versus Dobutamine (LIDO) Study, Efficacy and safety of intravenous levosimendan compared with dobutamine in severe low-output heart failure (the LIDO study): a randomised double-blind trial, Lancet 360 (2002) 196-202; DOI: 10.1016/S0140-6736(02)09455-2.

84. V. S. Moiseyev, P. Poder, N. Andrejevs, M. Y. Ruda, A. P. Golikov, L. B. Lazebnik, Z. D. Kobalava, L. A. Lehtonen, T. Laine, M. S. Nieminen, K. I. Lie and RUSSLAN Study Investigators, Safety and efficacy of a novel calcium sensitizer, levosimendan, in patients with left ventricular failure due to an acute myocardial infarction. A randomized, placebo-controlled, double-blind study (RUSSLAN), Eur. Heart J. 23 (2002) 1422-1432. 